Correction

\title{
Correction to: Mesenchymal Stem Cell Deformability and Implications for Microvascular Sequestration
}

\author{
Herbert H. Lipowsky (iD, Daniel T. Bowers, Brittany L. Banik, and Justin L. Brown
}

Department of Biomedical Engineering, The Pennsylvania State University, 215 Hallowell Bldg, University Park, PA 16802, USA

Correction to: ANNALS OF BIOMEDICAL

ENGINEERING (2018)

https://doi.org/10.1007/s10439-018-1985-y

This article was updated to correct the spelling of author Brittany L. Banik's name.

Address correspondence to Herbert H. Lipowsky, Department of Biomedical Engineering, The Pennsylvania State University, 215 Hallowell Bldg, University Park, PA 16802, USA. Electronic mail: hhlbio@engr.psu.edu

The original article can be found online at https://doi.org/10.1007/s10439-018-1985-y. 